\title{
The research environmental impact disclosure
}

\author{
Yoram Reich $^{1} \cdot$ Matthias Finkbeiner ${ }^{2}$
}

Published online: 29 November 2021

(C) The Author(s), under exclusive licence to Springer-Verlag London Ltd., part of Springer Nature 2021

Just in the past 12 months, we have witnessed significant devastating environmental events including, fires in southeast Mediterranean and Balkan countries, in the US and elsewhere, floods in Europe and Asia, and extreme temperatures including their odd fluctuation. We are also aware of the amount of waste we generate and its impact on land and seas and the destruction of parts of our natural resources. We definitely need to work together towards changing the course of events.

If we wanted, as researchers, not as other citizens, to contribute to sustainability or to address environmental challenges, what should we do?

The usual answer of the scientific or technological community would be: do more research on sustainability, lifecycle impact, and promote the publication and dissemination of such research hoping it will contribute to our stated cause. This is the classic response of these communities: observe an issue, study it, propose technical solutions, and implement them. Solutions could be: electric cars to replace gasoline cars; or recycling plastic to prevent its becoming waste, or lightweighting or renewables. There are, however, limitations to this approach. for example, do we really consider the long-term effects of a "sustainable" technology? How do we actually define a "sustainable" technology? Do we consider all sustainability aspects and technology's side effects? There is not always a silver bullet and there could be many consequences and trade-offs: take the example of a study comparing vehicle concepts in China that found that electric or hybrid cars reduce global warming but at the same time increase mineral resource scarcity, and ecological and human toxicity (Zeng et al. 2021). Following this, mineral scarcity has significant implications for the environment

Yoram Reich

yoramr@tauex.tau.ac.il

1 School of Mechanical Engineering, Tel Aviv University, Tel Aviv, Israel

2 Chair of Sustainable Engineering, Technical University Berlin, Berlin, Germany
(Rebello et al. 2021). In the same context, another study confirmed, that the environmental impact of an electric vehicle in China on eutrophication and acidification is significantly higher than from internal combustion engines (Sun et al. 2021). Another example is the trade-off between carbon and water footprint for biofuels (Berger et al. 2015). There is also more specific criticism about the concept of sustainability and its impact on addressing environmental challenges (e.g., Benson and Craig 2014; Fiala 2008). There is also an increasing need to address the social and economic sustainability dimension (Finkbeiner et al. 2010). Besides the sustainability-driven research, that explicitly deals with an assessment of these aspects, the vast amount of research studies do not deal with the environmental or sustainability implications at all. The question about their impacts on the environment remains unresolved. Technology development is definitely needed for human welfare and well-being, but it may need some regulation and a kind of instruction or information leaflet; just like any medicine has a package insert that provides warnings and informs about adverse effects.

For all types of research, we have to address two issues: what is the impact of the research activities themselves on the environment, and what is the impact of the outcome of the research? The former topic is receiving more attention lately (e.g., Fardet et al. 2020; Ligozat et al. 2020; Williams et al. 2021). Ligozat et al. (2020) rules include recommendations that are included in this editorial. Specifically, rule 7 "Evaluate the impact of your research practices," is one that we adopt in this editorial: reflecting on the impact of our own research through a Research Environmental Impact Disclosure (REID) ${ }^{1}$ to be discussed later. Moving a step further, we could claim that following the principle of reflexive practice (Reich 2017), if we designed our research to be more effective and efficient, it would also be more sustainable; we do think that those working on sustainability research should try to make their research sustainable. This is not only a moral obligation but will serve our self-interests.

\footnotetext{
$\overline{1}$ Not to be confused with the journal name acronym RIED Research in Enigneering Design.
} 
Going back to the two issues related to research sustainability, there could be all four combinations including sustainable research that develops some sustainable solutions or research with zero impact on the environment that has a significant damaging effect on the environment. Let us consider some examples. If we develop a method for additive manufacturing (AM), it may save material used in traditional manufacturing but lead to waste more due to excessive use of prototyping or it may use toxic materials (Gao et al. 2015). Specific research on AM could identify where it stands and what are its long-term goals concerning this landscape (Bours et al. 2017). Another example is research on modularity that may allow reducing environmental impact because it allows for upgrading systems hence increasing their life but initially, it might harm the environment because it requires developing and manufacturing unnecessary interfaces and casings (Engel and Reich 2015). Some research such as on design theory or selection methods may find it more difficult to state environmental impact but perhaps this could be done depending on the particular topic. For example, research on axiomatic design might improve the ability to create functionality independent modules, making the aforementioned issues related to modularity applicable here.

Note that we are not making any judgment about the quality of research or its review outcome based on the REID. The goal is to increase awareness and allow the community to reflect on its activities. To illustrate, we could work on polluting products (such as gasoline cars) trying to improve them without attention to sustainability. The REID of such research might state that this research does not try to improve the environmental impact but that the outcome may be harming or improving it as a side effect. One complaint might be that if we consider sustainability as critical, we should abandon the desire to improve such cars and move to research products that have a much better positive environmental impact. Such discussion could be part of the REID but is outside the scope of the review decision.

We anticipate that if we, researchers, start to think about these issues proactively, our research activities would, and perhaps their outcome, be more sustainable.

As a scholarly journal, we want to contribute to addressing the environmental crisis. We can contribute in at least two ways along the lines mentioned above. One way is to encourage research papers on design for sustainability or design to reduce environmental impact. Such research may contribute to addressing environmental challenges. It could be realized by creating special issues and forming a dedicated team of experts that will review papers quickly. These ideas belong to the traditional approach of doing science: we provide better service to authors and attract them to work and publish on these topics.

But we want to go a step further. We want to increase the awareness of all the community of design researchers on this topic and make sure the community considers these issues in its work. One approach to foster this is to ask of every submission, a statement regarding its impact on the environment-the Research Environmental Impact Disclosure (REID). We are not aware of such initiative elsewhere but disclosures regarding ethical issues of conducting research are common. We are requested to disclose any conflict of interests when we submit a paper and we are requested to provide information regarding approval of studies on people or animals by some board of the authors' institution. These, however, are quite simple statements. Reflecting on the environmental impact of research is more involved. We need to strike a balance between simple, insignificant, without review statement to elaborated, meaningful and reviewed REID.

We do not have expertise in judging what the best way is. We have not tried it and observed its outcome. This seems to be the first initiative of its kind in a journal. We do not attempt, therefore, to create a template such as the one shown in Table 1 to be filled by all researchers and coerce each submission into this template. We understand that there are very different types of papers submitted to the journal and different types of REID would fit them.

One approach may be to request with any paper a short statement, in which authors discuss their sustainability contribution. Of course, authors can write something there even though their project might be a bit mediocre in terms of sustainability, but at least it would make authors think and they would have to provide some information proactively. Initially, authors can design their statements taking into account this editorial, reflecting on their research and its relation to sustainability. Reviewers and editors could read it and provide feedback to the authors. We would make it clear to reviewers that the REID does not impact the editorial decision regarding the paper because some reviewers' decisions might be influenced negatively by research that has negative environmental impacts.

The REID will appear with the paper before the references section and readers could reflect on it. It is within the interest of authors to make this REID as best reflecting their research impact on the environment.

We intend to start requesting a REID in a separate file or fill information through the submission process as we do with the conflict of interest statement. Authors can use the template in Table 1 or create their own template or format. Diversity will allow us to experiment, learn, and develop different types of REIDs for different types of research. We also envision that the REID initiative will drive deeper discussion on sustainability and ecological impact as these 
Table 1 Potential reporting template with guiding questions and some exemplary answers

\begin{tabular}{|c|c|c|c|}
\hline & Guiding question & Research process & Research outcome \\
\hline 1 & $\begin{array}{l}\text { What are your submission's intended posi- } \\
\text { tive impacts on environmental, economic, } \\
\text { and social sustainability? }\end{array}$ & $\begin{array}{l}\text { Reduced material consumption for proto- } \\
\text { types... }\end{array}$ & Greenhouse gas reduction, high qualified jobs \\
\hline 2 & $\begin{array}{l}\text { Are you aware of potential negative impacts } \\
\text { on global environmental, economic, and } \\
\text { social sustainability that could result from } \\
\text { the further development of your research? }\end{array}$ & Solvent emissions & $\begin{array}{l}\text { High water demand, use of special materials } \\
\text { that are produced under critical working } \\
\text { conditions }\end{array}$ \\
\hline 3 & $\begin{array}{l}\text { What is the basis for your answers? How } \\
\text { confident are you that they are correct? }\end{array}$ & $\begin{array}{l}\text { Personal intuition, personal knowledge, } \\
\text { survey, evidence from the literature, meas- } \\
\text { urements, ... } \\
\text { Confidence is fair }\end{array}$ & $\begin{array}{l}\text { Example A: LCA study performed, confi- } \\
\text { dence high } \\
\text { Example B: Qualitative expert judgment } \\
\text { based on literature, confidence low due to } \\
\text { knowledge gaps }\end{array}$ \\
\hline 4 & $\begin{array}{l}\text { How would you recommend your research } \\
\text { be developed and improved upon in the } \\
\text { future? }\end{array}$ & $\begin{array}{l}\text { Reduce solvent emissions or replace the } \\
\text { solvent, study the research process impact } \\
\text { quantitatively }\end{array}$ & $\begin{array}{l}\text { Example A: Perform a social LCA to better } \\
\text { understand the social impact of the critical } \\
\text { materials used } \\
\text { Example B: Perform an environmental LCA } \\
\text { or another form of quantitative screening }\end{array}$ \\
\hline
\end{tabular}

will be related to any research now. Indeed, these concepts already create debate in the community (e.g., Fiala 2008; Marcuse 1998).

Authors wishing to include discussion on these items in the REID are more than welcome.

\section{References}

Benson MH, Craig RK (2014) The end of sustainability. Soc Nat Resour 27(7):777-782

Berger M, Pfister S, Bach V, Finkbeiner M (2015) Saving the planet's climate or water resources? The trade-off between carbon and water footprints of European biofuels. Sustainability 7:6665-6683

Bours J, Adzima B, Gladwin S, Cabral J, Mau S (2017) Addressing hazardous implications of additive manufacturing: complementing life cycle assessment with a framework for evaluating direct human health and environmental impacts. J Ind Ecol 21(S1):S25-S36

Engel A, Reich Y (2015) Advancing architecture options theory: six industrial case studies. Syst Eng 18(4):396-414

Fardet T, Hütten M, Lohmann S, Medawar E, Milucka J, Roesch JH, Rolfes JD, Schweizer J (2020) Making science organizations sustainable - the mission of the Max Planck sustainability network. Front Sustain 1:5

Fiala N (2008) Measuring sustainability: why the ecological footprint is bad economics and bad environmental science. Ecol Econ 67(4):519-525
Finkbeiner M, Schau EM, Lehmann A, Traverso M (2010) Towards life cycle sustainability assessment. Sustainability 2:3309-3322

Gao W, Zhang Y, Ramanujan D, Ramani K, Chen Y, Williams CB, Zavattieri PD (2015) The status, challenges, and future of additive manufacturing in engineering. Comput Aided Des 69:65-89

Ligozat AL, Névéol A, Daly B, Frenoux E (2020) Ten simple rules to make your research more sustainable. PLoS Comput Biol 16(9):e1008148

Marcuse P (1998) Sustainability is not enough. Environ Urban 10(2):103-112

Rebello S, Anoopkumar AN, Aneesh EM, Sindhu R, Binod P, Kim SH, Pandey A (2021) Hazardous minerals mining: challenges and solutions. J Hazard Mater 402:123474

Reich Y (2017) The principle of reflexive practice. Design Sci 3. https://doi.org/10.1017/dsj.2017.3

Sun X, Bach V, Finkbeiner M, Yang J (2021) Criticality Assessment of the life cycle of passenger vehicles produced in China. Circ Econ Sustain 1:435-455

Williams K, Kane B, Clarke C, Widdicks K (2021) The environmental impact of research communities: insights from conference sustainability chairs. XRDS 27(4):46-51

Zeng D, Dong Y, Cao H, Li Y, Wang J, Li Z, Hauschild MZ (2021) Are the electric vehicles more sustainable than the conventional ones? Influences of the assumptions and modeling approaches in the case of typical cars in China. Resour Conserv Recycl 167:105210

Publisher's Note Springer Nature remains neutral with regard to jurisdictional claims in published maps and institutional affiliations. 